\title{
Summary: Analysis of Alternative FBR Development Strategies
}

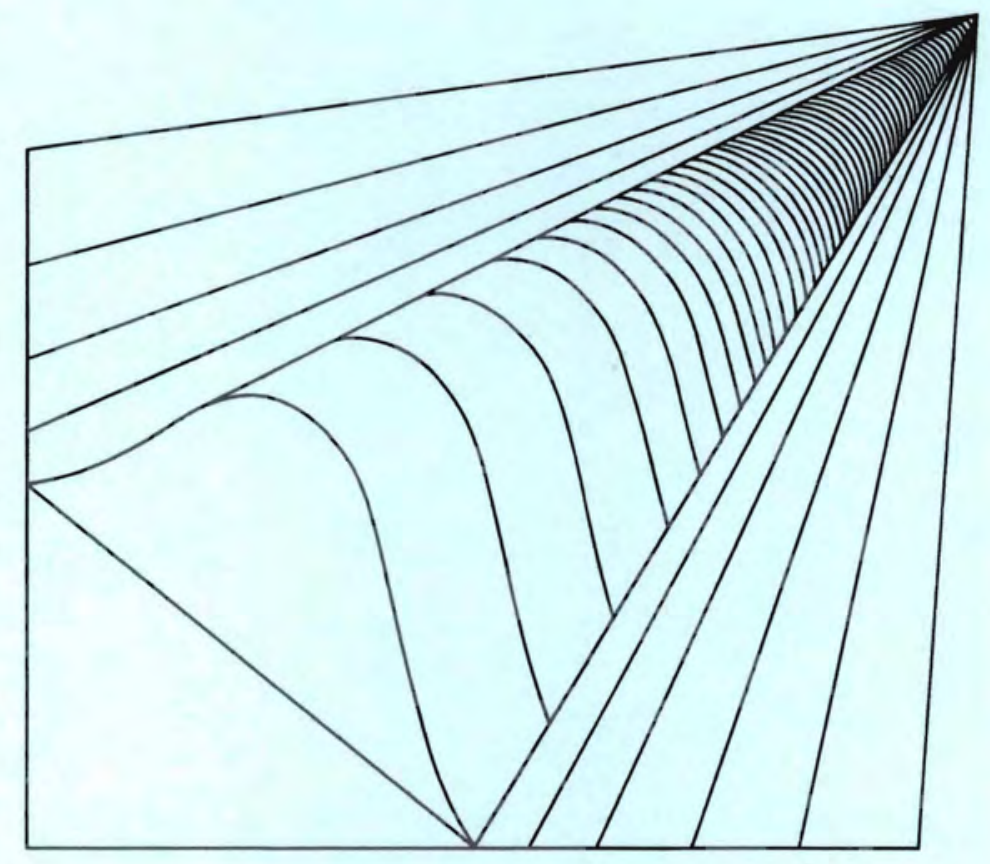

Prepared for the U.S. Department of Energy under Contract DE-AC06-76RLO 1830

Pacific Northwest Laboratory Operated for the U.S. Department of Energy by Battelle Memorial Institute 
This report was prepared as an account of work sponsored by the United States Government. Neither the United States nor the Department of Energy, nor any of their employees, nor any of their contractors, subcontractors, or their employees. makes any warranty, express or implied, or assumes any legal liability or responsibility for the accuracy, completeness or usefulness of any information, apparatus. product or process disclosed, or represents that its use would not infringe privately owned rights.

The views. opinions and conclusions contained in this report are those of the contractor and do not necessarily represent those of the United States Government or the United States Department of Energy.

\author{
PACIFIC NORTHWEST LABORATORY \\ operated by \\ BATTELLE \\ for the \\ UNITED STATES DEPARTMENT OF ENERGY \\ Under Contract DE-AC06-76RLO 1830
}
Printed in the United States of America
Available from
National Technical Information Service
United States Department of Commerce
5285 Port Royal Road
Springfield. Virginia 22151

Price: Printed Copy \$

$\therefore$ Microfiche $\$ 3.00$

NTIS

-Pages Selling Price

$\begin{array}{rr}001-025 & \$ 4.00 \\ 026-050 & \$ 4.50 \\ 051-075 & \$ 5.25 \\ 076-100 & \$ 6.00 \\ 101-125 & \$ 6.50 \\ 126-150 & \$ 7.25 \\ 151-175 & \$ 8.00 \\ 176-200 & \$ 9.00 \\ 201-225 & \$ 9.25 \\ 226-250 & \$ 9.50 \\ 251-275 & \$ 10.75 \\ 276-300 & \$ 11.00\end{array}$


PNL -3600

UC $-2,16$,

SUMMARY:

ANALYSIS OF ALTERNATIVE FBR DEVELOPMENT STRATEGIES

J. B. Burnham

December 1981

Prepared for

the U.S. Department of Energy

Under Contract DE-AC06076RLO 1830

Pacific Northwest Laboratory

Richland, Washington 99352 

ACKNOWLEDGMENTS

This is a brief summary of an extended study of alternative approaches to fast breeder development performed by Pac ific Northwest Laboratory for Jack Thereault, Department of Energy. The work was done by a research team under the management of Rod Fleischman and directed by John Burnham.

The detailed descriptions of analytical methods, data development and study results are contained in a series of topical reports. These reports are listed for the reader who is interested in more technical detail.

Piepel, G. F., G. W. Long, R. A. McLaren, (a) and C. E. Ford. (a)

1981. Probabilistic Estimates of U.S. Uranium Supplies. PNL-3595.

Boegel, A. J. and M. J. Clausen. 1981. Characterization of Alternative FBR Development Strategies. PNL-3596.

White, M. K. and E. T. Merri11. 1981. Evaluation of the Commercial FBR Introduction Date. PNL-3597.

Fraley, D. W. and J. B. Burnham. 1981. A Method for Selecting FBR Development Strategies in the Presence of Uncertainty. PNL-3598.

Although the results and conclusions of the study are the sole responsibility of the research team, we would like to thank many others who contributed data, programing, editing, consultation, and review. Our apologies and thanks also to those whom we have inadvertently excluded from the list below.

Car 1 Andersen

W. W. Ballard

J. A. Bartel1

S. J. Beard

R. L. Beatty

D. M. Blanchfield

Gary Boyer

Ramesh Budwani

Donald Cox

E. M. Craig

John H. Crowley

Stanley M. Davies

Tom DiFranc isco

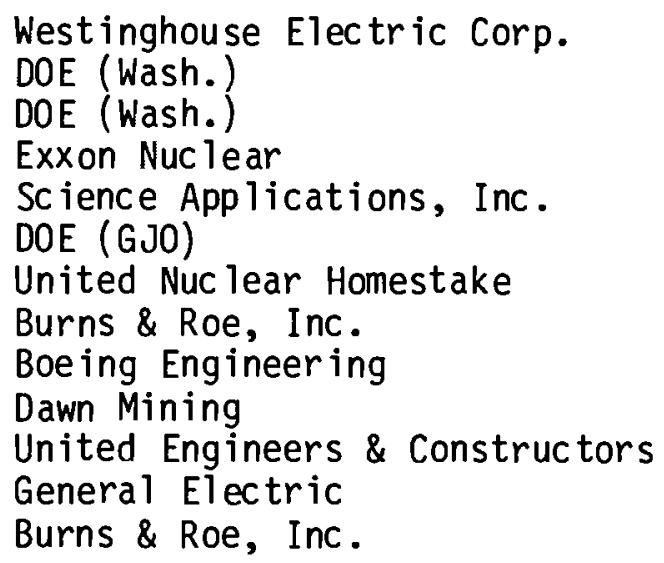

(a) Union Carbide Corporation, Oak Ridge, TN. 
T. A. Dillon

Lawrence Droutman

Lonnie Foley

Simcha Gol an

Neal Goldenberg

Noe 1 Gonzaga

Don W. Gray

Norton Haberman

Tom Hand

Hugh Kendrick

J. Daniel Khazzoom

L. Kovisars

R. C. Liikalla

John R. Longenecker

R. C. Malan

Allan S. Manne

P. J. McGoey

John A. Patterson

Howard Rohm

James Schuyler

C. L. Storrs

David Thomas

L. D. Williams

Bart Withers
DOE (Wash.)

Westinghouse Electric Corp.

PNL

Bechtel National Inc.

DOE (Wash.)

S. M. Stoller

TRW

DOE (Wash.)

Westinghouse Electric Corp.

DOE (Wash.)

University of California

MET Research

PNL

DOE (Wash.)

DOE (GJO)

Stanford University

PNL

DOE (Wash.)

DOE (Wash.)

Pacific Gas \& Electric

C-E Power Systems

DOE (Wash.)

PNL

Portland General Electric 


\section{SUMMARY}

This report summarizes the comparative evaluation of alternative strategies for the development of the commercial fast breeder reactor (FBR) in the United States. Ideally, a commercial FBR would become available when it is economically competitive in the marketplace. However, it is not possible to determine with complete certainty either the point of parity of the FBR in the power market or the time required for development. Unlike other FBR planning efforts, this study uses probability distributions to explicitly treat these sources of uncertainty.

For planning purposes, a range of possible FBR development paths called strategies were selected for evaluation. These strategies, designed to be technically and economically feasible, were expressed in terms of the timing and nature of facilities/research and development programs required to reach full power operation of the first commercial FBR. Four of the seven strategies resulted in a large ( 1457 MWe) FBR as an end point, the other three in a 1000-MWe plant. Probability distributions were calculated for total strategy costs and time to completion. For the seven strategies analyzed, the costs (discounted 1980 do 11 ars) ranged from $\$ 1.8$ billion to $\$ 4.9$ billion; the completion times ranged from 24 to 55 years.

In order to compare and evaluate these strategies it was also necessary to understand the factors that determine the FBR's competitive date. The competitive date was calculated taking into account uncertainties in: 1) U.S. uranium supplies, 2) the nuclear industry's growth rate, 3) the capital costs of light water reactors (LWR) and fast breeder reactors, 4 ) the effects of LWR improvements, and 5) the effects of improved uranium enrichment facilities. The analysis showed that the large (1457 MWe) FBR would most likely be competitive if it came on-line in the decade 2025-2035. Results also indicated that, due to economies of scale, the large FBR would probably be competitive earlier than the smaller one.

The benefits to society of introducing a commercial FBR when it is economically competitive were evaluated with an econometric model, ETA-MACRO. 
The risks of being early or late with the FBR's development were also quantified. The analysis demonstrated that the cost to society of being late was far greater than that of being early.

The strategy completion dates, competitive dates, and benefits data were combined to calculate the benefits that could be expected from each strategy. The expected cost and the sum of the risks (too early and too late) were subtracted from the expected benefits to form a net benefit figure of merit which was used to compare strategies. Other comparison criteria such as risk aversion (looking for minimum risks) and mini-max (trying to minimize the worst outcomes) were also developed.

Based on these comparisons it was concluded that compressed strategies that resulted in a large commercial FBR on-line in 33 to 38 years are superior to those which proceed on a longer time schedule or produce a 1000-MWe FBR. The study also concluded that a prudent planning strategy would seek to avert the large penalty for a late FBR development by making a near-term dec ision to begin a large development plant. 


\section{CONTENTS}

\section{ACKNOWLEDGMENTS}

ij $i$

SUMMARY

1.0 INTRODUCTION

2.0 APPROACH .

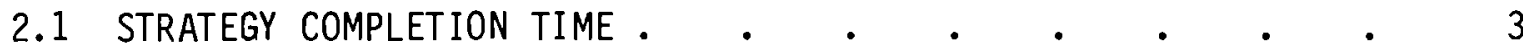

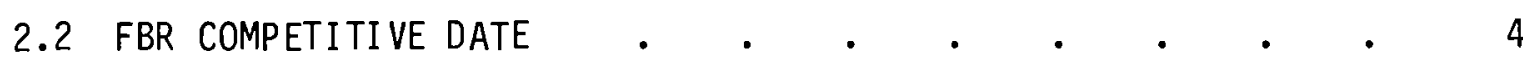

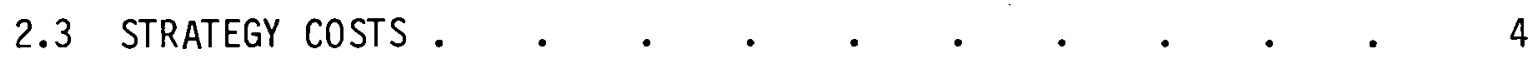

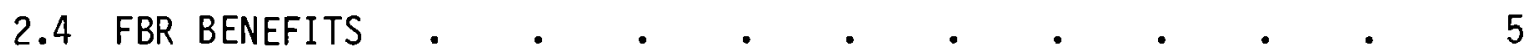

2.5 ANALYSIS $. \quad . \quad . \quad . \quad . \quad . \quad . \quad . \quad . \quad . \quad . \quad . \quad 5$

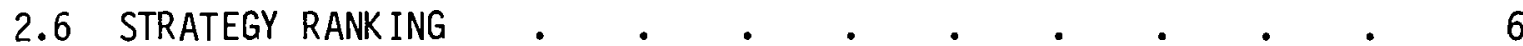

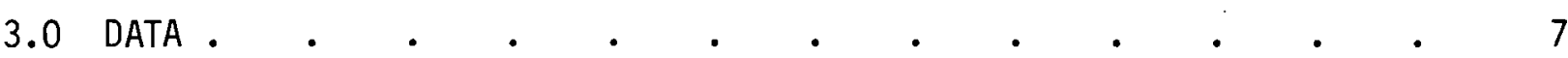

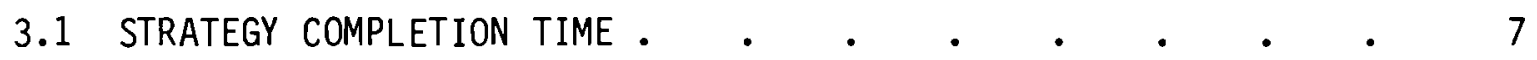

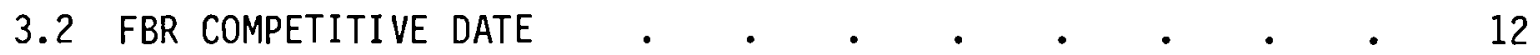

3.3 STRATEGY COSTS .

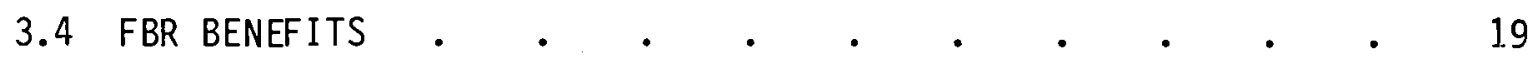

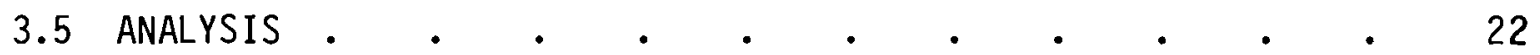

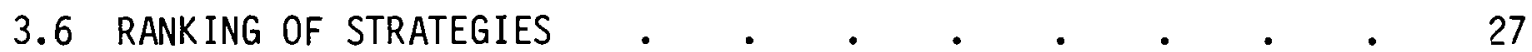

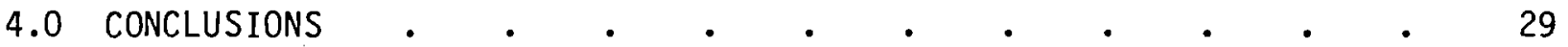

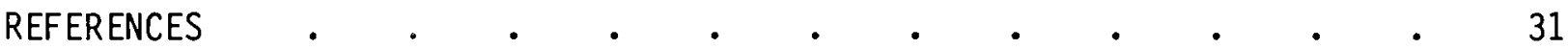




\section{FIGURES}

1. Diagram of Analys is of Alternative Strategies for FBR Development 3

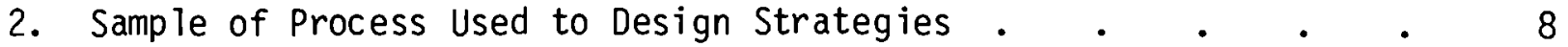

3. Distribution of Probable Completion Time for Sequential Strategy . 11

4. Quantity of $\mathrm{U}_{3} \mathrm{O}_{8}$ Available at Full Recovery Cost $\quad$. . . 13

5. Nuclear Power Capacity Projections as a Function of Elasticity of Substitution with Expected Uranium Resources . . . . . 15

6. Probability Density Function for a 1000-MWe or a 1457-MWe FBR Becoming Economically Competitive with an LWR $\quad$. $\quad . \quad$. $\quad 17$

7. Capital Cost Probability Density Functions for 1000-MWe and

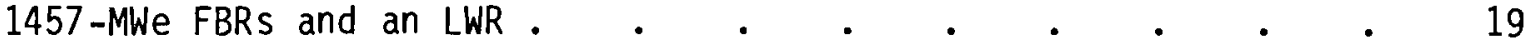

8. Gross FBR Benefits, for a 40-Year Time Period, as a Function of

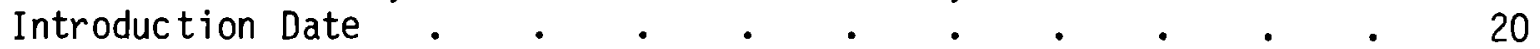

9. Benefits of Late FBR Introduction for Three Introduction Dates . 21

10. Probable Year of Completion of Sequential Strategy $\quad$ - . $\quad 23$

11. Comparison of Completion and Competitive Dates for an $80 \%$

Confidence Interval. . . . . 24

\section{TABLES}

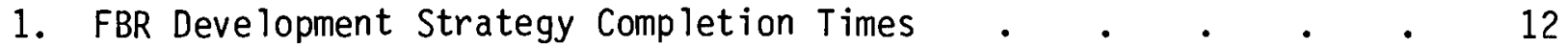

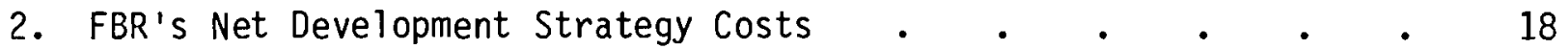

3. Discounted Expected Strategy Costs . . . . . . . . . 18

4. Standard Deviation of Strategy Completion Dates and $80 \%$ Confidence Interval . . • • • • • • • • • 24

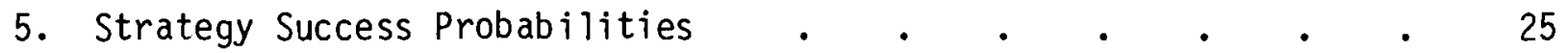

6. Early and Late Risks . . . . . . . . . . . . . . 26

7. Strategy Net Benefits . . . . . . . . . . . . 26

8. Summary of Strategy Rankings . . . . . . . . . . . 28 


\subsection{INTRODUCTION}

Development of the fast breeder reactor (FBR) has been vigorously debated over the past few years. After careful analysis, world energy experts (DOE 1980) concluded that the introduction of the FBR by advanced nations would not materially change the world's nuclear proliferation problems. This conclusion, combined with the refusal of the U.S.S.R., West Germany, France, Great Britain, and Japan to join the United States' unilateral decision to delay FBR development, has led the United States to a new commitment to the continuation of this program.

Past studies have comprehensively evaluated FBR development (Manne 1974, Manne and Yu 1975, AIF 1979, Droutman 1980, Richels 1979, Stauffer et al. 1975). These studies have weighed the risks of FBR development against the risks of dependence on foreign oil; compared the probability of developing a technologically successful FBR with the probability of developing alternative energy technologies; and compared the potential environmental problems of an FBR with those of other energy technologies (AEC 1974). Simply stated, these studies concluded that, while technical, environmental, and political problems remain to be solved, the inherent risks of FBR development are small compared to the benefits of energy independence and the implementation of a technology based on an essentially renewable resource. Therefore, this analysis does not reexamine past arguments, but moves ahead to determine a preferred strategy for developing the FBR.

Many strategies can be derived by varying the number, size, and timing of the developmental and prototypical FBRs that have to be designed, constructed, and operated before arriving at a mature FBR. This analysis characterizes seven strategies. These strategies, which cover a range of viable development approaches, were selected to investigate the implications and uncertainties associated with size, timing, and cost. Strategies that assumed the purchase of foreign technology were not included in the analysis.

One of the first problems encountered in defining an optimal development strategy is that of establishing a probable date by which an FBR would be commercially competitive. This analys is estimated a probable date by modeling 
a utility's future decision to construct either a mature FBR or an advanced LWR based on a comparison of estimated FBR and LWR lifetime power costs.

The FBR's commercial competitiveness is highly dependent on U.S. uranium supplies, FBR capital costs, and nuclear industry growth, all of which are highly uncertain. When these parameters are specified in a deterministic analysis and the values are varied over ranges that characterize the data's uncertainty, the calculated competitive date usually spans a period from year 2000 to 2050. Because the relative probability of the combination of variables that yield a given competitive date is unknown, it is difficult to assign a higher credibility to any one date than to any other. A probabilistic analysis was chosen to address this problem. All important variables were expressed as probability functions and the dates for commercial FBR competitiveness were then also derived in probabilistic terms.

To calculate FBR competitiveness it was necessary to express uranium supply and nuclear industry growth in probabilistic terms. With the help of the Department of Energy's (DOE) Grand Junction Office (GJO) and Union Carbide Company a probabilistic supply curve was developed for uranium resources over $0.01 \%$ grade. The approach to the nuclear growth data was innovative in that current restrictions to nuclear industry growth, interactions between GNP and energy, and competition with other energy forms were included in an econometric model to yield a probabilistic estimate of nuclear growth.

To compare alternative strategies, the probability functions derived for the time, cost, expected benefits, and financial risks of the various strategies were reduced to usable measures. Finally, these measures were combined in a decision analysis model that provided an objective method to compare the alternatives and to thus indicate a preferred FBR development strategy.

This paper first describes the approach used in the analysis. It then sumarizes the data used in the study and its treatment in the analysis. Finally, the results and conclusions of the analysis are briefly presented. 


\subsection{APPROACH}

The objective of the study was to identify a preferred path for the development of a commercial fast breeder reactor. The approach to this analysis is shown schematically in Figure 1. Each of the major components of the analys is is described briefly.

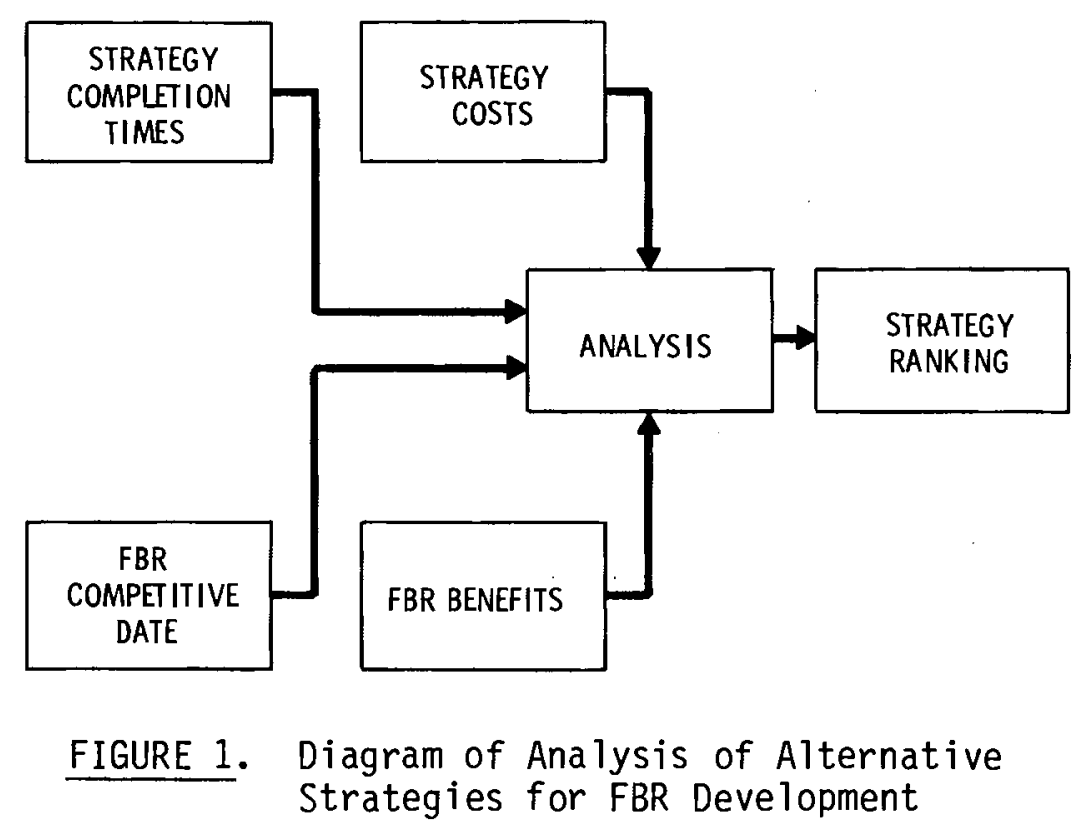

\subsection{STRATEGY COMPLETION TIME}

Seven strategies were developed in some detail with the assistance of experts on FBR design and construction. The strategies were designed to cover a range of possible approaches to the further development of the FBR. The strategies and the methods used to characterize them are described in Boegel and $\mathrm{Cl}$ ausen (1981) and are summarized in Section 3.1. An important part of the characterization is the time required to complete each strategy. For the purpose of this study it was assumed that a strategy was complete when the first commercial FBR achieved full power operation. A "commercial" FBR was defined as a mature, fifth-of-a-kind plant entirely financed by utilities. 
The time to complete a series of plants was analyzed in a network model. The model explicitly included the uncertainties in construction and licensing times. It also contained estimates of the effects of the loss in skills arising from a protracted (sequential) approach. The model also addressed the increased uncertainty associated with licensing plants in a compressed schedule in which minimal operating experience is available. A completion probability distribution for each strategy was developed from this data.

\subsection{FBR COMPETITIVE DATE}

The ideal strategy would be timed such that the mature plant would be available just when the FBR is commercially competitive. Thus, calculating the FBR's probable competitive date was fundamental to analyzing this relationship.

A competitive date was defined as the date at which a mature FBR could reach full power and have projected lifetime costs equal to or less than a light water reactor (LWR) completed in the same year. This date is strongly influenced by: the relative FBR/LWR capital costs; the U.S. uranium supply; and the growth of the LWR industry. It is less affected by: improvements in LWR technology; introduction of an advanced converter reactor; and reduction of the uranium tails assay. These factors were considered probabilistically by White and Merrill (1981), who derived a probability distribution for the date that the FBR will be competitive.

\subsection{STRATEGY COSTS}

Boege 1 and $\mathrm{Cl}$ ausen (1981) developed the costs as well as the completion times of the seven strategies. Costs were derived probabilistically. The calculated cost distributions included the capital costs of the plants in the strategy, fuel cycle costs, operating costs, and the cost of the base technology program. A credit was allowed for the sale of energy generated by the developmental plants built. The returns from this sale of energy defray to a great extent the cost of development. 


\subsection{FBR BENEFITS}

The benefits associated with the introduction of the FBR were essential to the analysis. These benefits were calculated with an econometric model, ETA-MACRO, developed by Alan Manne of Stanford (Manne, Condap and Preckel 1981). The model consists of two parts, ETA, which models the energy section of the economy, and MACRO, which models the rest of the economy.

ETA has the capability of considering up to 30 technologies, including the ir availability dates, rates of deployment, and initial and mature costs. Hence, it is ideal for calculating the economic impact of future energy sources.

MACRO models such factors as the potential growth of the economy, the interaction between energy and the gross national product, the change in energy demand with price, and the ability of labor and capital to substitute for energy.

Fraley and Burnham (1981) described how the model was used to calculate the FBR benefits. They estimated benefits that can be expected if the FBR is competitive at a certain date (say 2025) and is available at that date. For each competitive date they also derived a function which expresses the reduced benefits that can be expected if the FBR is not available until later than that date. These latter relationships were useful in analyzing a strategy's timing and estimating the penalty for a strategy being "late." The penalties for developing the technology too early were calculated on the bas is of development funds being spent earlier than necessary. The increased present value of these expenditures (over the optimally timed) was defined as the risk of being too early.

\subsection{ANALYSIS}

The data described above were developed in the form of probability density functions. To be useful in the decision process the data had to be reduced to a more manageable form. Fraley and Burnham (1981) described the mathematical operations performed on the data to generate measures for comparing strategies. 
Statistical analys is of the strategy's time and cost data yielded expected values, ranges, and confidence levels. (For a discussion of statistical terms see Appendix A of Fraley and Burnham 1981). The confidence levels can best be illustrated by example: A decision-maker might well ask the dol1 ar level that we are $90 \%$ confident will not be exceeded for a given strategy.

More complex analysis was afforded by combining the completion date, competitive date, and benefits data. For example, a combination of completion and benefits data was used to estimate expected strategy benefits. As mentioned earlier, certain combinations were used to calculate the economic risk of completing a strategy too early (before it is competitive) or too late (after it is competitive).

It is also useful to calculate worst cases, which can be used to gain perspective on the decision. For example, a costly situation arises when the FBR is needed at the earliest probable date, but is ready at the latest probable date. At a specific level of confidence (such as 10\%), the calculated maximum late risk expresses the lost benefits associated with this condition. Maximum early risk may be similarly calculated.

\subsection{STRATEGY RANKING}

The analytical measures described in the previous section were combined to rank the alternative development strategies. One of the more comprehensive methods of ranking came from the calculation of net strategy benefits. The net benefit is equal to the expected gross benefits less the expected strategy cost less the strategy's total risks.

A strategy can also be selected on the basis of averting risk; only the strategy's risks are considered. In this case, one ranks highest the strategy with the lowest total risk, where total risk is the sum of a strategy's early and late risks.

Another method of ranking strategies is afforded by the so-called mini-max criterion. Here, the decision-maker seeks the strategy that has a minimum worst case outcome. For example, strategies might be ranked on the bas is of maximum late risks; the strategy with the minimum value would, of course, be ranked highest. 


\subsection{DATA}

The analysis used a great deal of data. Some of the data were available from the literature, some of it was developed from expert opinion, and some was calculated.

\subsection{STRATEGY COMPLETION TIME}

Boegel and Clausen (1981) concluded that a number of factors strongly affect the time (and time uncertainty) it takes to develop the FBR from its present state of technology to the point that it is commercially competitive. These factors and the ir impacts are:

- scale-up - Scaling a plant up from a given size, for which there is design and operating experience, to a larger size results in extra time and uncertainty.

- operating experience - The more operating experience that can be incorporated into successive plant design, the less the uncertainty.

- personnel retention - Attrition of skilled personnel due to long delays between design and construction of successive plants increases uncertainty.

- licensing - A protracted schedule affords more operating experience and time to develop licensing criteria, which tends to reduce licensing uncertainties. A protracted schedule has the opposite effect. The attrition of NRC licensing personnel increases licensing uncertainty.

- component testing - When sufficient time is allowed to complete component testing of one plant before starting design of the follow-on plant, uncertainties are reduced.

- vendor commitment - A long period of time between construction of plants forces vendors to maintain only a low-level of participation, which tends to increase time uncertainties.

- utilities commitment - A protracted schedule allows maximum time for utilities to technically and economically evaluate the FBR. This tends to reduce uncertainty in the utility's decision to commit to FBR deployment. 
To account for these factors, we designed the alternative strategies (Boege $\mathrm{l}$ and $\mathrm{Cl}$ ausen 1981) to cover a wide range of time, to vary the amount of component testing done, and to vary the degree of scale-up required. Combinations of plant size and timing alone offer an almost limitless number of development options. The goal was to identify a wide range of possible approaches without being exhaustive. In all cases, of course, it was essential that the developmental design be both technically and economically sound.

An example of the process used to define strategies is illustrated in Figure 2. The particular strategy shown is the Sequential Strategy. The first plant in the sequence was sized at 1000 MWe. A recent study of a 1000-MWe development plant was used as a reference (Boeing 1981). This had the advantage of yielding the most recently available design and cost data for a plant of this size. The second plant was designated as a prototype. It

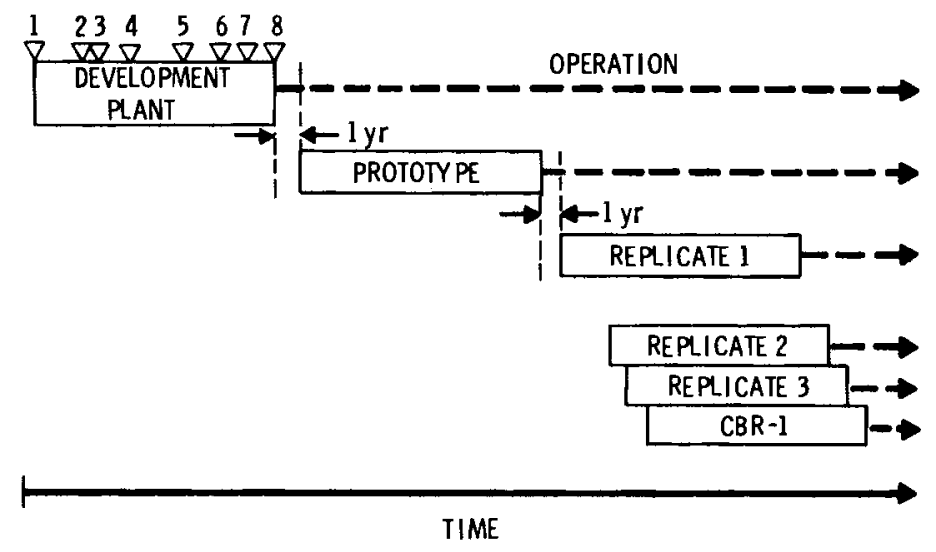

1. SITE SELECTION/CONGRESSIONAL AUTHORIZATION

2. ISSUE CONSTRUCTION PERMIT/CONSTRUCTION AUTHORIZATION

3. COMPLETE COMPONENT TESTING

4. SET REACTOR VESSEL

5. SUBMIT FSAR

6. ISSUE OPERATIONAL LICENSE/AUTHORIZE FUEL LOADING

7. LOAD FUELIINITIAL CRITICALITY

8. COMMERCIAL/FULL POWER OPERATION

FIGURE 2. Sample of Process Used to Design Strategies 
represented a technically sound scale-up of $45 \%$ from the developmental plant. The 1457-MWe size was the largest that could be built under current NRC guidelines, which limit the maximum thermal capacity of a plant. It was assumed that the prototype was the first plant of the series to be licensed. The replicate plants are duplicates of the prototype. It is through the replication of a standard design that savings in time and cost can be realized. The fifth-of-a-kind was assumed to be a mature plant. Most (about $90 \%$ ) of the benefits to be gained by replication were assumed to have been realized by the time this plant was built. This plant was designated as Commercial Breeder -1 (CBR-1). Its derived costs were used as the reference in the calculation of the date the FBR would probably be competitive (see Section $3.2)$.

In the Sequential Strategy illustrated in Figure 2 the prototype plant is timed such that its design is not begun until the demonstration plant has been operating for one full year. Likewise, the first replicate plant is not begun until the prototype has operated for a year. This strategy illustrates the effect of operating experience as well as scale-up. It also illustrates the effects of attrition of design, construction, and licensing personnel due to the protracted time period of the developmental strategy. These effects were found to be of major importance since average length of time an engineer would be expected to work on a reactor design is roughly 3 years, and the time between design or licensing projects in this strategy would be almost 8 years.

A similar strategy, called Compressed, was designed with the same sequence of plants as the Sequential Strategy. To investigate the effects of timing and to produce a large FBR in a shorter period of time, the linkages between plants were such that the start of one plant was overlapped with the construction of the previous plant to the maximum practical extent. The design work on the prototype was assumed to begin after the component testing phase of the demonstration plant had been completed. The first replicate was started when the operating license for the prototype had been issued. This strategy optimizes the use of skilled design and licensing personnel but loses some of the advantages of reactor operating experience. 
Two more strategies--Delayed Sequential and Delayed Compressed--were designed by assuming that the initiation of both the Sequential and Compressed Strategies was delayed by 5 years. This delay tested the effect of an extension of calendar time to completion without altering the size or linkage of plants in the two strategies.

A considerably different approach to FBR development was investigated in the Component Testing Strategy. Here it was assumed that, in lieu of a demonstration plant, the next 10 years would be committed to an intensive and deliberate component testing program. At the end of this time period work would begin on a 1000 MWe prototype reactor that would draw heavily on the testing results and the CDS design. This is replicated and, hence, CBR-1 (the fifth-of-a-kind, mature plant) is of 1000 MWe capacity. Although the mature plant is relatively small (hence higher capital cost), this approach avoids the time, cost, and uncertaintites associated with scale-up. However, this strategy is penalized by an attrition of construction and licensing personnel.

Two other strategies minimize scale-up by developing 1000-MWe mature plants. The Direct Prototype Strategy assumes that the first plant, similar to the CDS design, would be licensed. When the component testing phase of this plant is complete, the design of the first replicate is started. The lack of licensing or operating experience contributes time uncertainty. However, the firm commitment to an accelerated FBR commercialization would predictably lead to a high level of vendor participation, which should have the effect of decreasing uncertainty.

The Direct Replicate Strategy is similar to the Direct Prototype except that the developmental plant is operated for 1 year to gain operating experience before beginning to design the first replicate plant. Since Replicate 1 is the first plant to be licensed, the operating experience should result in a shorter licensing time than what could be expected from the Direct Prototype Strategy. However, the long delay between design and construction of the developmental and first replicate plants results in personnel attrition, which adds to time uncertainty. 
Each of the seven strategies was analyzed in a network model. This model broke down the schedule for the design and construction of each plant into nine components. Experts in scheduling reactor construction were asked their opinion on the time distribution of each of the nine components. The consensus data were entered for each component as a probability distribution in the network model. Linkages between plants were also incorporated into the analysis. For example, in the Sequential Strategy (see Figure 2) site selection for the prototype plant cannot begin until the developmental plant has operated for 1 year. Replicate 1 is linked to the prototype in the same way.

A sample of the resulting probability distribution of completion time is shown in Figure 3. Note that the expected time to completion is 46 years with shortest and longest completion times 41 and 50 years, respectively. It is interesting to compare these times with what we call schedule time. Schedule time is derived from the simple addition of the planned times for each of the design, construction, licensing and operation steps. When schedule times are

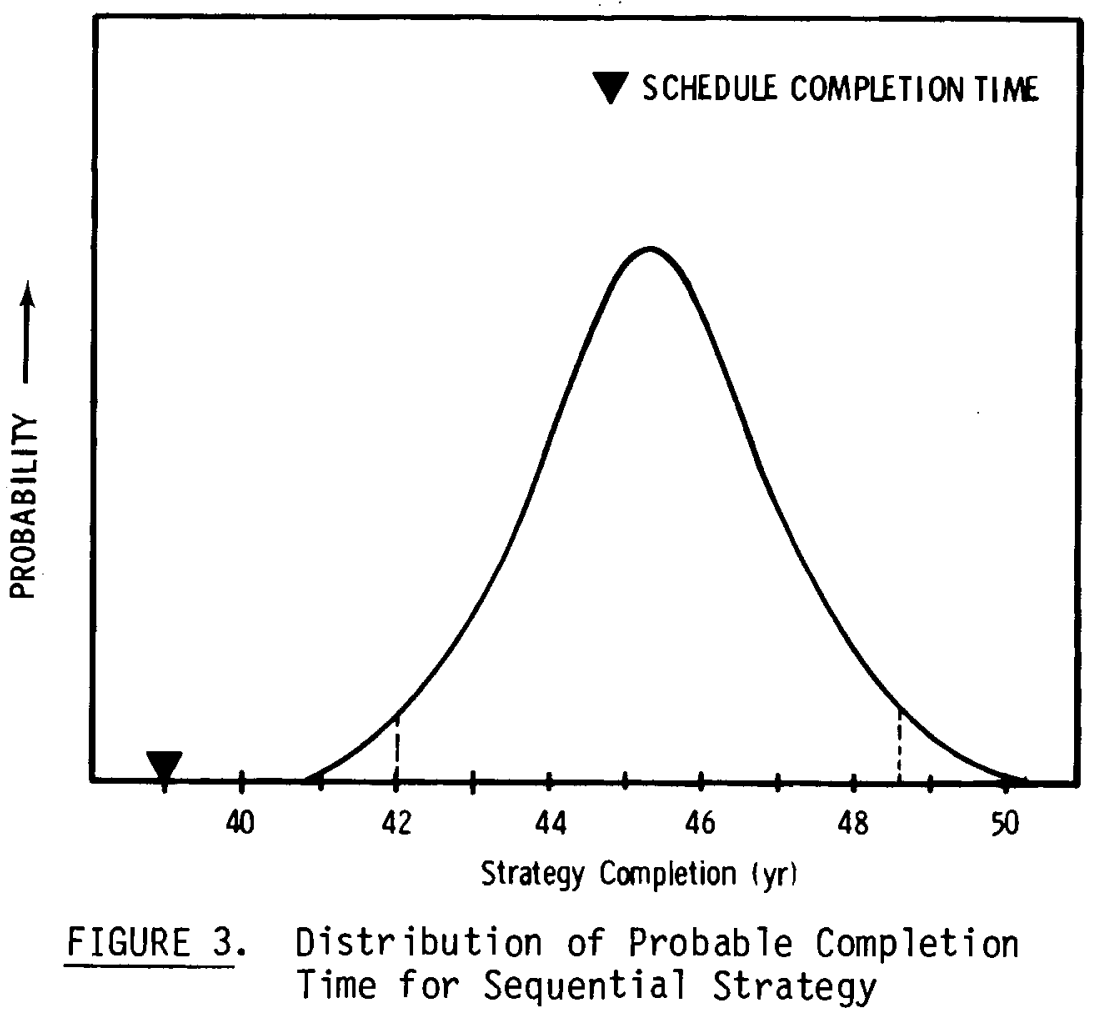


used (as is often the case in program planning), little consideration is given to the probability of slippage; more importantly, no accounting is made of the impact of one project's delay on subsequent projects in the program. The net result is that program schedule times almost invarably understate the time requirements of a complex program. This is shown in Figure 3 , where an example schedule completion time falls totally outside the probability distribution. This means that for the plants and sequencing of this stategy there is essentially no chance of completion (full power operation of CBR-1) in the 39-year schedule time.

Table 1 lists the completion time data for all seven strategies. Note that the strategies have a range of 28 to 50 years in the expected time to completion. The total range of possible completion times is 24-55 years.

TABLE 1. FBR Development Strategy Completion Times

\begin{tabular}{lllll}
\multicolumn{1}{c}{ Strategy } & & \multicolumn{3}{c}{ Completion Time (Years) } \\
\cline { 1 - 1 } Ain. & & Expected & Max. \\
A--Sequential & & 40.8 & 45 & \\
B--Delayed Sequential & & 45.8 & 50.3 & 55.4 \\
C--Compressed & & 30 & 33 & 37.8 \\
D--Delayed Compressed & 34 & 38 & 42.8 \\
E--Component Testing & 34 & 37 & 42 \\
F--Direct Prototype & 24 & 28 & 32 \\
G--Direct Replicate & & 25.3 & 29 & 33.2
\end{tabular}

\subsection{FBR COMPETITIVE DATE}

A probability distribution was developed for the dates that the FBR would be competitive with an LWR completed in the same year. Details of this part of the analysis are given in White and Merrill (1981). The calculation included the following variables:

- U.S. uranium supply

- growth of nuclear industry

- LWR improvements 
- enrichment tails assay

- capital and operating costs for FBR and LWR.

The U.S. uranium supply function was developed by PNL with the assistance of the Grand Junction Office of DOE and Oak Ridge National Laboratory (Piepel et a1. 1981). This part of the study used the GJO data base. Quantities were converted from resources in the ground, as reported by $D O E$, to yellowcake recovered from the mill. The costs were based on full cost recovery (all costs including return on investment, taxes, etc.) as contrasted to DOE's forward cost basis. Figure 4 illustrates these results. It should be noted

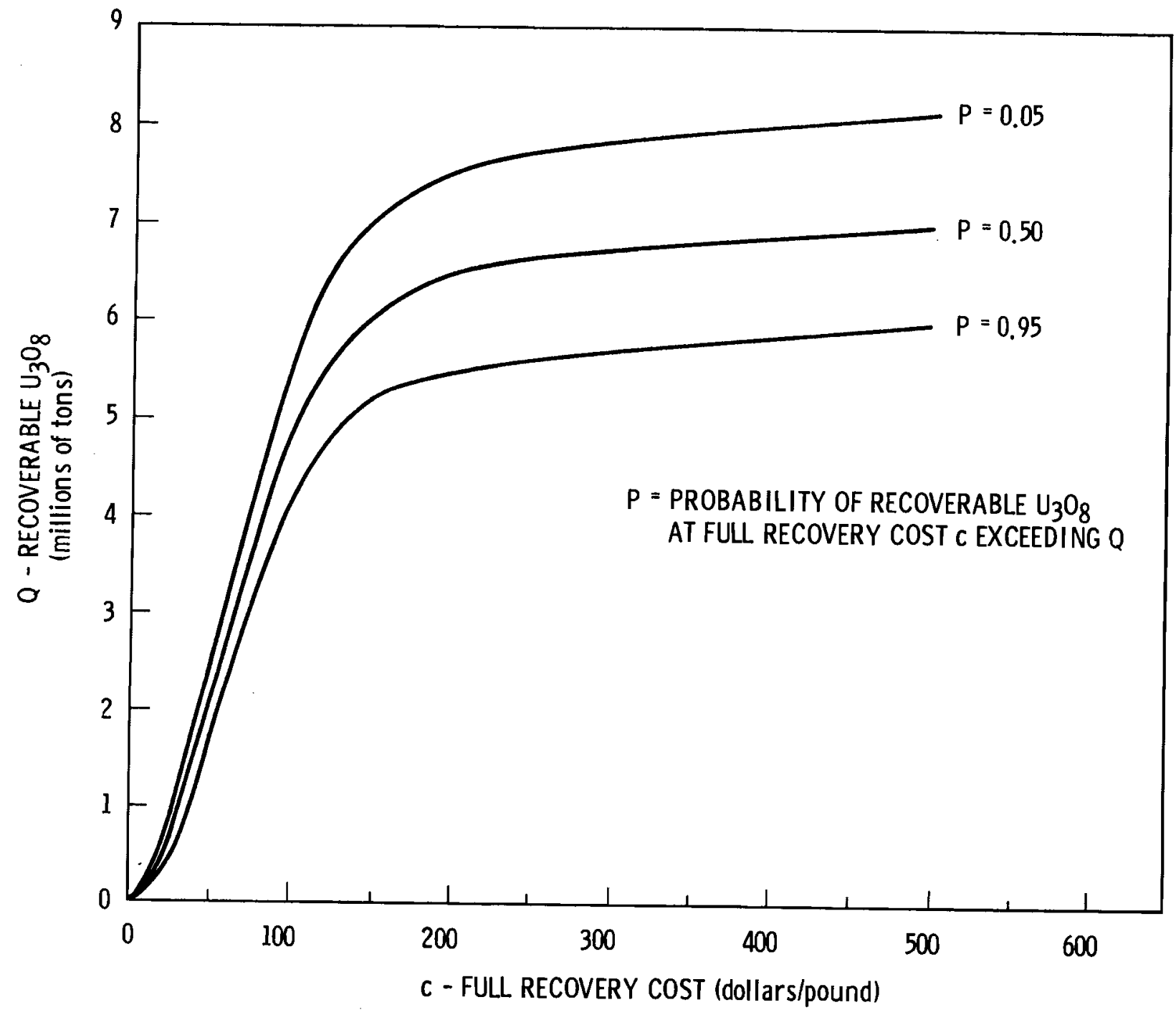

FIGURE 4. Quantity of $\mathrm{U}_{3} \mathrm{O}_{8}$ Available at Full Recovery Cost 
that on ly resources with minimum grade over $0.01 \% \mathrm{U}$ are included in the data base used in this analysis. Further, the analyses of uranium supply are based entirely on U.S. resources and U.S. consumption. While there may be some export and some import of uranium, it is assumed that over the long term the net is near zero.

Growth of the nuclear industry was calculated using the econometric simulation model ETA-MACRO (Manne 1977). Two types of input data were specified for ETA-MACRO: 1) cost data for nuclear energy and alternative energy sources (coal, oil, etc.), and 2) the econometric relationship between economic growth and the impacts of energy, labor, and capital on the economy. The relationship between economic growth and the three factors (energy, labor, and capital) is called the elasticity of substitution, $\sigma$. Values to be used for the elasticity of substitution were derived from data supplied by members of the Energy Modeling Forum (EMF), an organization created by the Elecric Power Research Institute to improve practical applications of large energy models. The sensitivity of growth to uranium supply and to $\sigma$ were tested. It was found that the latter had a far greater influence on nuclear growth than the former.

Figure 5 shows the results of this analysis. The growth of LWR generating capacity is shown as a function of four equally likely values of $\sigma$ for a given uranium supply. The details of these calculations are discussed in White and Merri11 (1981).

As uranium becomes more expensive, LWR improvements, which do not require large capital investment, will be made to reduce uranium consumption. A current design for a pressurized water reactor (PWR) with a once-through fuel cycle was used as the reference LWR. These reactors are typically refueled annually and achieve a fuel exposure of about 30,000 MWD/MT. Several retrofit options are available to reduce uranium requirements. These options include: increased burnup, lattice changes, improved fuel management and control design, enrichment zoning/fertile blankets, end-of-cycle coastdown, and the full use of batches in the startup core. 


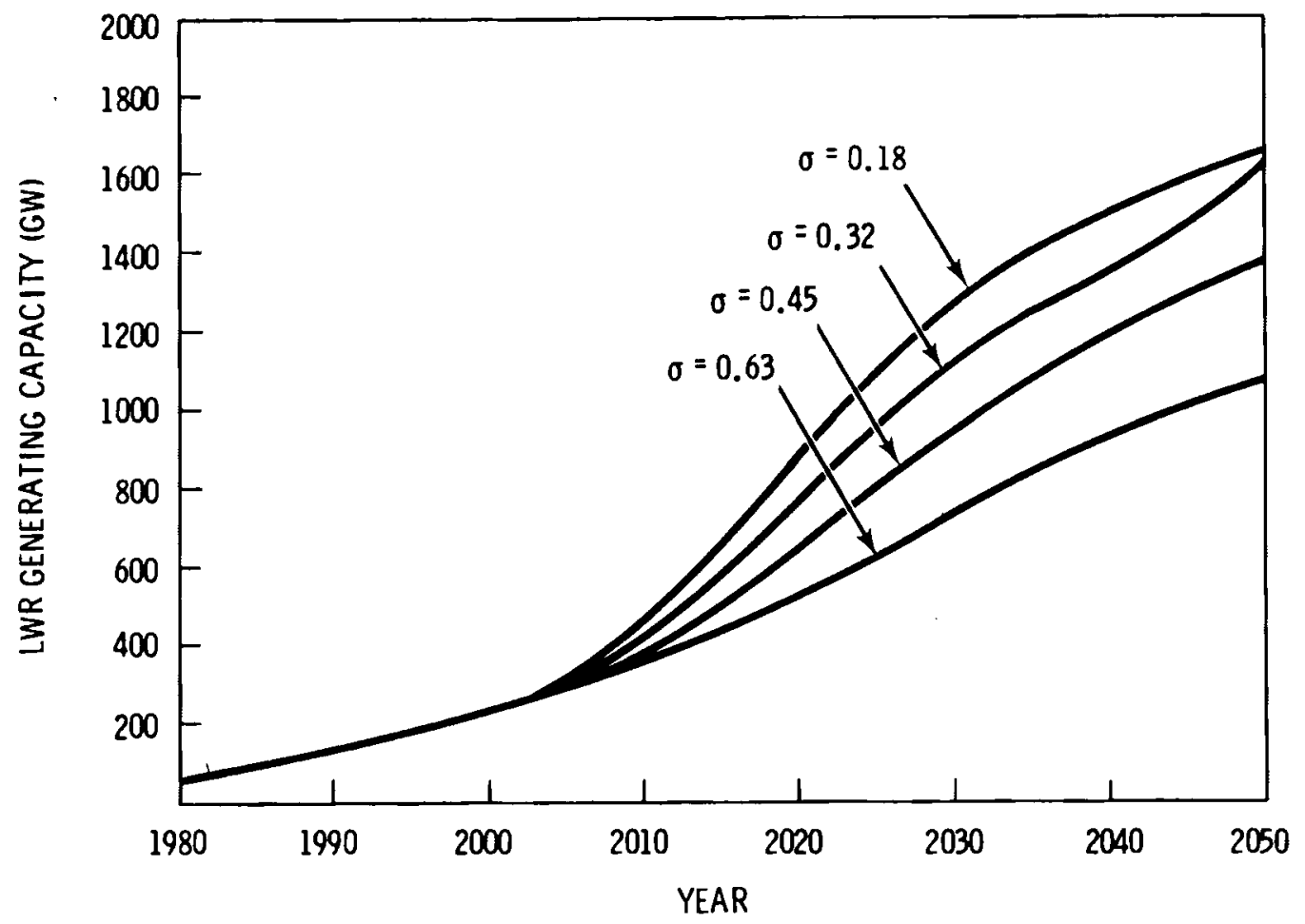

FIGURE 5. Nuc lear Power Capac ity Projections as a Function of Elasticity of Substitution with Expected Uranium Resources

Although fuel savings are higher with a 12 -month refueling cycle than with an 18-month cycle, the latter cycle is finding some favor for reasons of maintenance and capacity factor. It is also not clear when improved cycles might be implemented or how rapid the conversion might be. Our study assumed the 12-month and 18-month refueling cycles to be equally likely. Transition from the current PWR fuel cycle to an improved cycle was assumed to occur at a uniform rate between 1988 and 2000 . The improved fuel cycles, when fully implemented, amount to an average decrease in uranium consumption of about $20 \%$.

No other advanced reactor systems were assumed implemented before the FBR. Analys is showed that even if these other systems were available early in the next century, they afford only a small cumulative uranium savings before the FBR will be available. Therefore, implementation of the systems would have little impact on the date that the FBR becomes economically competitive. 
The current enrichment tails assay is $0.2 \%$. When uranium costs increase, there will be an incentive to decrease the tails assay. Several programs are underway to increase the efficiency of the enrichment process. Rather than trying to predict the probability of success of the various programs, we analyzed the significant variable, the tails assay, assuming that the transition from $0.2 \%$ to $0.1 \%$ tails would begin in 1995 . The $0.1 \%$ value was chosen because it is technically feasible with any of the processes under consideration. For purposes of the calculation we modeled the transition at a uniform rate that causes the minimum disruption of the mining industry. The impact on the FBR's competitive date of further reducing the tails to $0.05 \%$ was found to be minimal--a 1- to 2-year delay.

Operating costs of the LWR and FBR were needed to calculate their respective energy costs. Operation and maintenance costs and fuel cycle costs were derived from data prepared for the Nonproliferation Alternative Systems Assessment Program (NASAP DOE 1980). The NASAP estimates of construction and operating costs for various fuel cycle facilities were used to calculate fuel cycle costs.

Finally, all of these important variables were incorporated into a computer program, EDWIN, which was written to calculate the competitive date distribution. The technique used to simultaneously incorporate into the calculations all of the important variables and their probability distributions is described in White and Merri11(1981). Figure 6 shows the results of these calculations. Note that the large (1457 MWe) FBR will probably be competitive earlier than the sma11 (1000 MWe) one. This is because the smaller FBR has the higher capital cost (in dollars per installed kilowatt).

\subsection{STRATEGY COSTS}

This section sumarizes the cost distributions derived for each of the seven strategies described in Section 3.1. The probabilistic cost distributions of the individual plants in a strategy were developed by synthesizing the opinions of cost experts on reactor manufacturing and of architect/ engineers. In addition to the capital costs, the strategy's costs include 


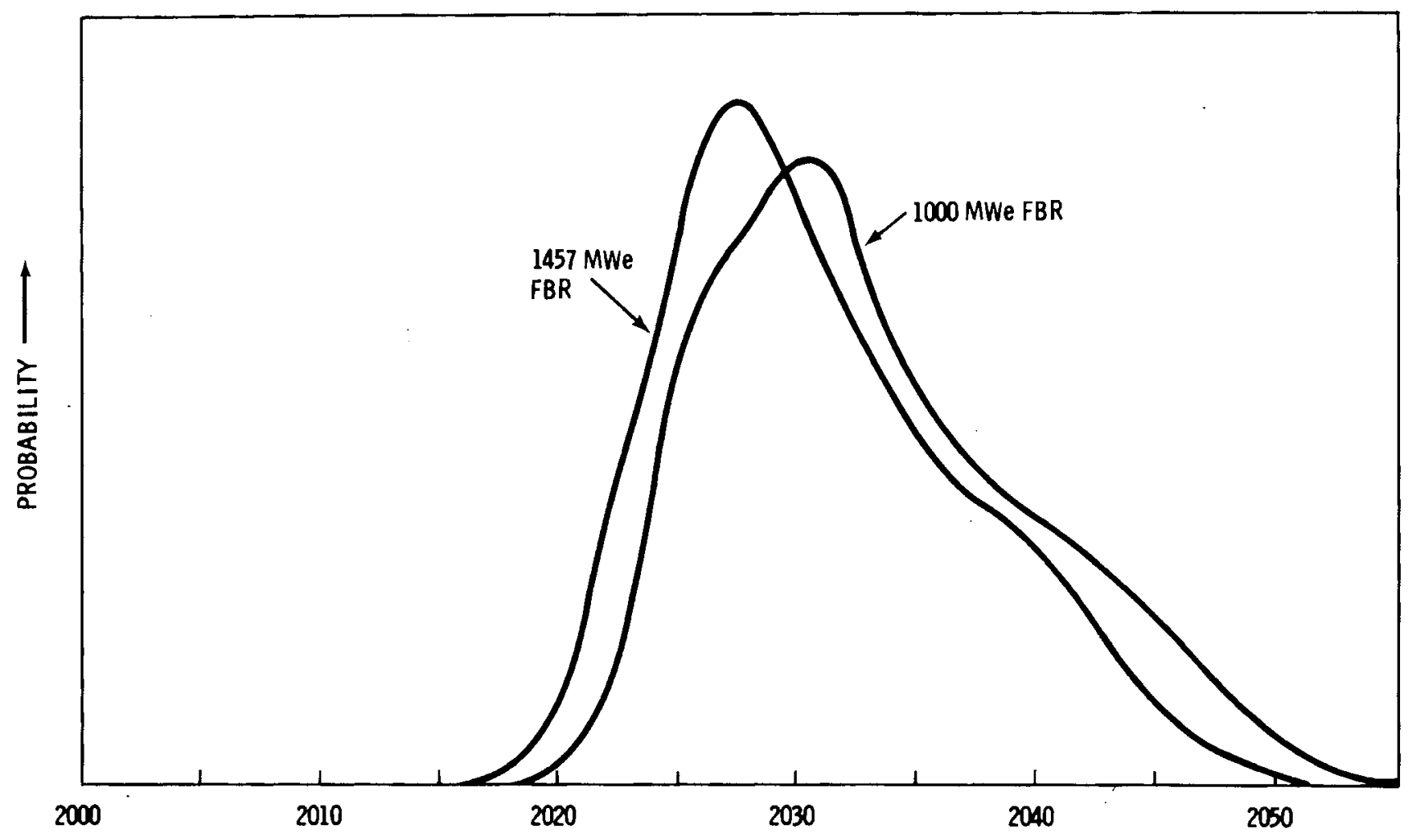

FIGURE 6. Probability Density Function for a 1000-MWe or a 1457-MWe FBR Becoming Economically Competitive with an LWR

operating and maintenance costs, fuel cycle costs, base technology costs, and the possible cost of a warranty to utilities who purchase the early replicate plants to ensure that their lifetime costs are no greater than an LWR built in the same year. A credit is allowed for the value of the power sales over the plants' lifetimes. The net undiscounted strategy lifetime costs are shown in Table 2. Since the power sale credits exceed the costs, the table shows negative values for the strategy costs (i.e., a net income). However, as shown in Table 3, the discounted costs are positive. The costs change sign when discounted because the large expenditures for plants and R\&D come in the early part of the strategy while the income is realized late in the strategy. The discounting effect diminishes the influence of future (as compared to present) dollar flows. 
TABLE 2. FBR's Net Development Strategy Costs

\begin{tabular}{|c|c|c|c|}
\hline \multirow[b]{2}{*}{ Strategy } & \multicolumn{3}{|c|}{ (Billion \$ 1980) } \\
\hline & Min & Expected & Max \\
\hline A-- Sequenti al & -14.6 & -13.2 & -10.8 \\
\hline B--Delayed Sequential & -14.5 & -13.1 & -10.7 \\
\hline C--Compressed & -14.8 & -13.5 & -11.3 \\
\hline D--Delayed Compressed & -14.7 & -13.4 & -11.1 \\
\hline E--Component Testing & -1.4 & -1.07 & -.52 \\
\hline F--Direct Prototype & -1.5 & -1.2 & -.58 \\
\hline G--Direct Replicate & -1.06 & -.5 & .57 \\
\hline
\end{tabular}

TABLE 3. Discounted Expected Strategy Costs

\begin{tabular}{|c|c|c|c|}
\hline Strategy & $\begin{array}{c}\text { Billion } \\
\begin{array}{c}\text { Lowest } \\
\text { Cost }\end{array}\end{array}$ & $\begin{array}{c}\text { iscounted } \\
\text { Expected } \\
\text { Cost } \\
\end{array}$ & $\begin{array}{c}5 \% \text { to } 1980 \\
\text { Highest } \\
\text { Cost } \\
\end{array}$ \\
\hline A-- Sequential & 1.83 & 2.34 & 3.24 \\
\hline B--Delayed Sequential & 2.00 & 2.39 & 3.12 \\
\hline C--Compressed & 2.10 & 2.78 & 3.96 \\
\hline D--Delayed Compressed & 2.25 & 2.79 & 3.76 \\
\hline E--Component Testing & 3.42 & 3.55 & 3.75 \\
\hline F--Direct Prototype & 4.01 & 4.19 & 4.58 \\
\hline G--Direct Replicate & 4.13 & 4.39 & 4.91 \\
\hline
\end{tabular}

Other parts of the study required capital cost data for both the LWR and FBR. It is important to the calculation of both the competitive dates ( Section 3.2) and the FBR's benefits (Section 3.4) that the capital costs of both the LWR and the commercial FBR (CBR-1 in Figure 2) be developed consistently; that is, the estimates must be based on the same construction locale and the same date of completion. Figure 7 shows these cost distributions. It should be noted that the LWR and FBR estimates are paired in that a low LWR cost implies low site costs, low labor rates, etc. It was assumed that an FBR 


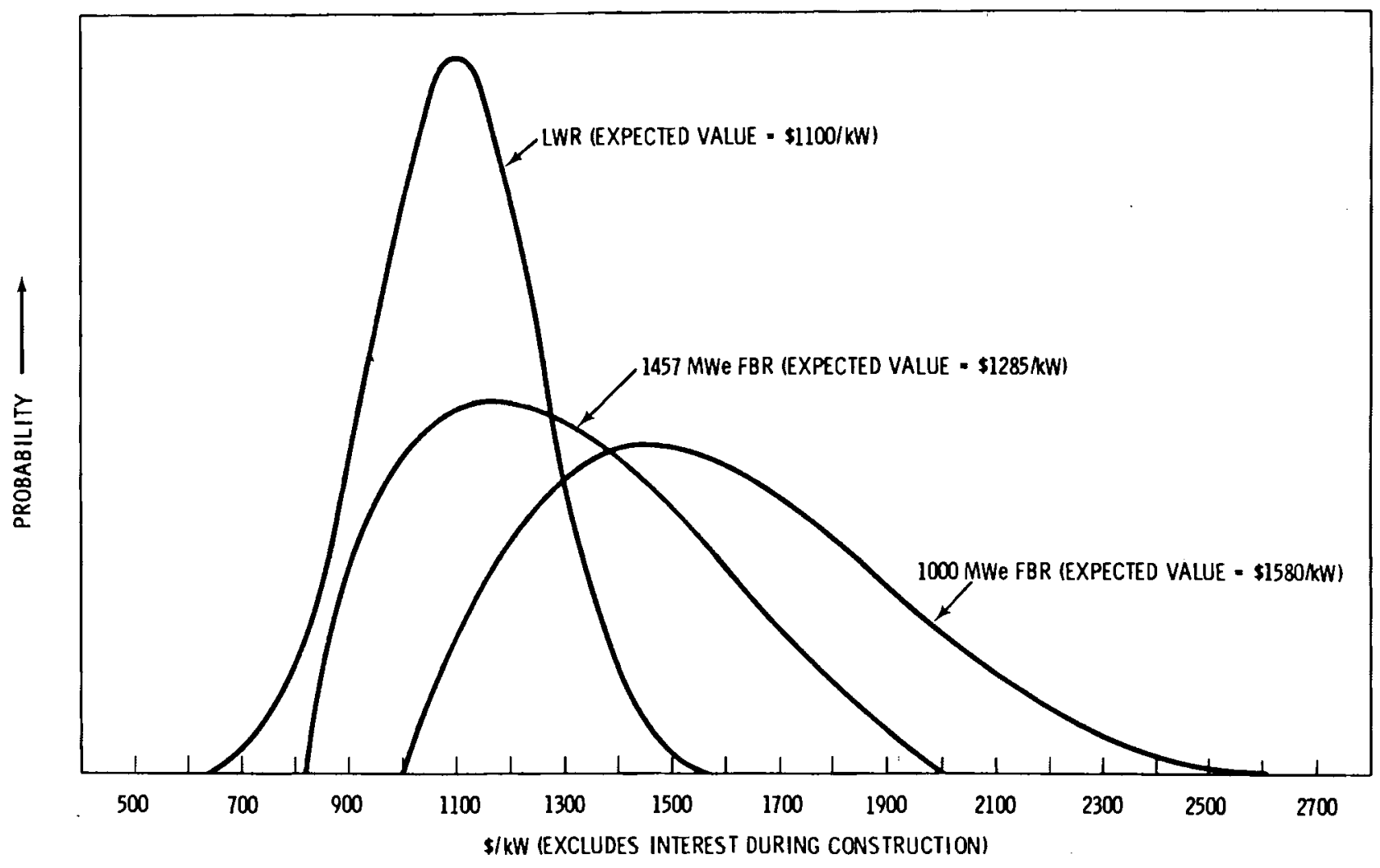

FIGURE 7. Capital Cost Probability Density Functions for 1000-MWe and 1457-MWe FBRs and an LWR

built on the same site at the same time would enjoy the same conditions and would tend to be on the low side of the FBR cost distribution. All costs are in 1930 dollars. Costs for interest during construction are not included in this figure; these add some 30 to $40 \%$, depending on the interest rates and construction period.

\subsection{FBR BENEFITS}

An important element of the analysis was to determine the benefits to society that can be expected from the introduction of a commercially competitive FBR. If it is competitive, it will, by definition, replace some more expensive energy form. Since less will have to be spent for energy, other sectors of the economy can be expected to benefit. As discussed in Section 2.4 these effects were studied with the ETA-MACRO econometric mode1. 
The benefits that $c$ an be expected from a timely introducton of a commercial FBR are shown in Figure 8. These benefits, discounted at $5 \%$ to 1980 , are the difference in U.S. consumption (GNP less capital investment) with and without the FBR. This curve represents the benefit to society of having a commerical FBR available "on time" (when it is economically competitive). If it is competitive in a given year, say 2025, but is not available until some time later, benefits will be foregone. Numerous runs were made with ETA-MACRO

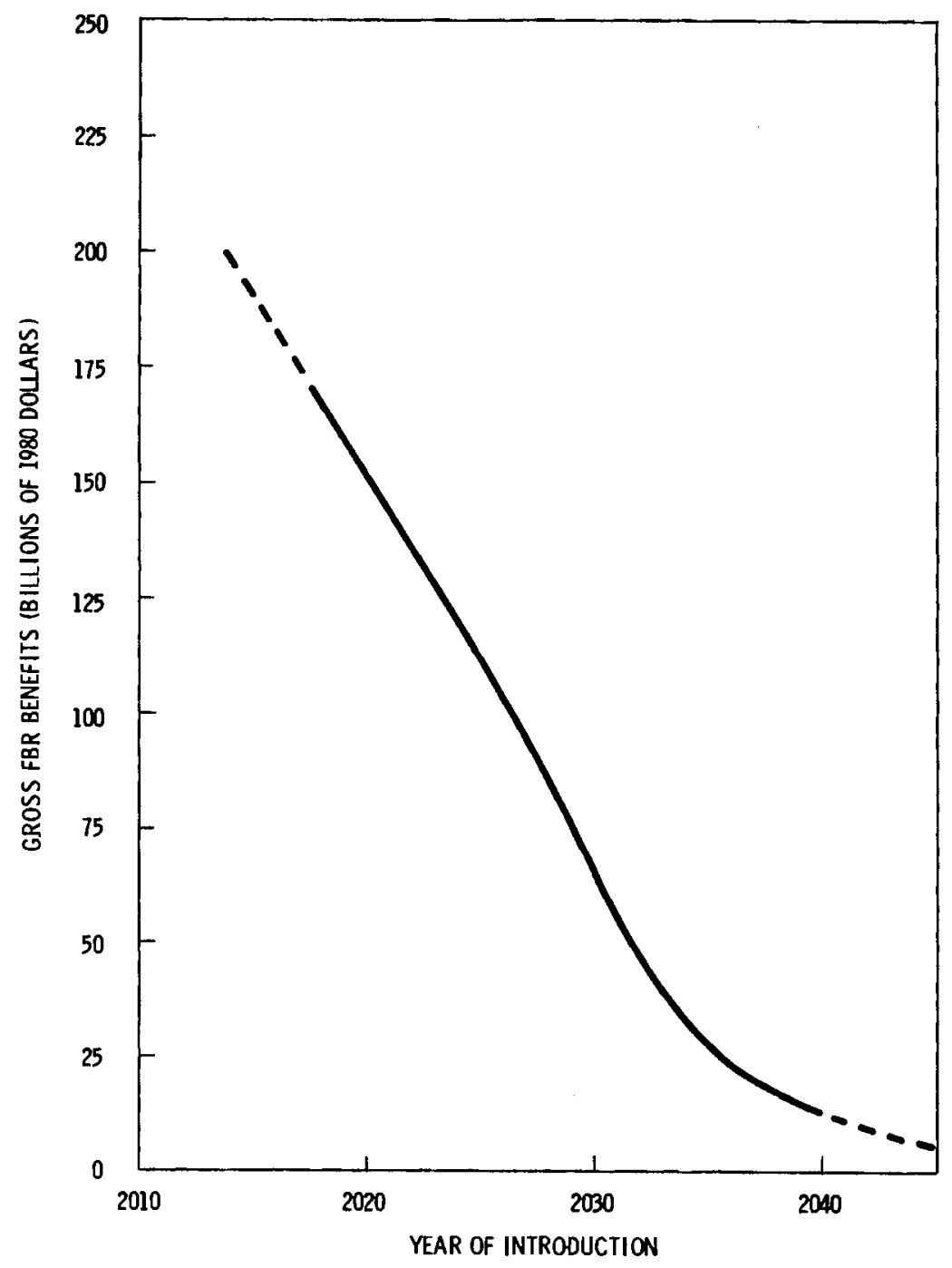

FIGURE 8. Gross FBR Benefits, for a 40-year Time Period, as a Function of Introduction Date 
(see Figure 9) to establish this relationship, which was used to calculate the economic cost of being late with the FBR's development. For a discussion of the methods and data used, see Chapter 3 in Fraley and Burnham (1981).

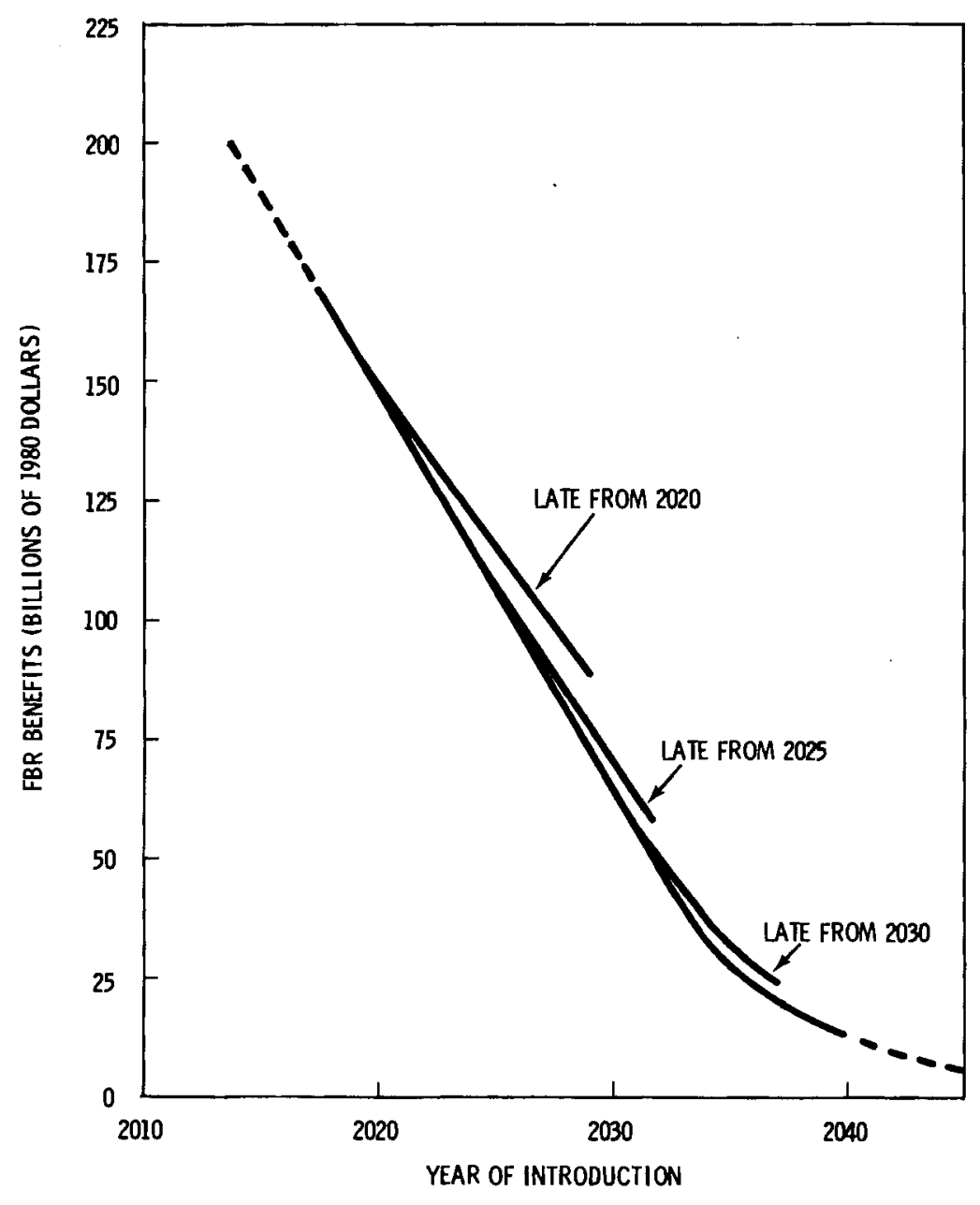

FIGURE 9. Benefits of Late FBR Introduction for Three Introduction Dates 


\subsection{ANALYSIS}

The analysis of the data discussed can be classified simply as follows:

1. statistical analys is of the probability distributions

2. comparison of completion dates with competitive dates

3. calculation of the risks of a strategy being completed too early or too late

4. calculation of the strategy's net benefits

5. analys is of worst possible outcomes.

Statistical analysis of the data identified expected values, ranges, and confidence levels. From data presented in Section 3.1 the Sequential Strategy is expected to be completed in about 45.5 years. Assuming that the development starts in 1981, the expected year of completion is 2026.5, with earliest completion about 5 years earlier and latest completion about 6 years later. It is also useful to use portions of this distribution. For example, if the earliest $10 \%$ and latest $10 \%$ of the distribution is "chopped off, "then we can define a range within which we are $80 \%$ confident of the strategy being complete. These results are shown for the Sequential Strategy in Figure 10. Similar statistical operations were performed on the strategy's cost and on the competitive date probability distributions. This analysis allows us to answer questions such as: "If the Sequential Strategy were adopted, by what date would you be $90 \%$ confident that a commercial FBR could be on-line?" These statistical parameters were also useful for other parts of the analys is, which are discussed later.

Table 4 gives the statistical results calculated for strategy completion times. The times have been translated to calendar time by assuming that the development starts in 1981. The standard deviation of the time distribution is a measure of the uncertainty of the estimates. Referring to the table one can notice an apparent anomaly. The two Compressed Strategies ( $C$ and $D$ ) exhibit the smallest standard deviations, and, hence the least uncertainty in the ir completion times. Intuitively, one mighty reason that a developmental approach that overlapped plants and reached completion in a "hurry" should 


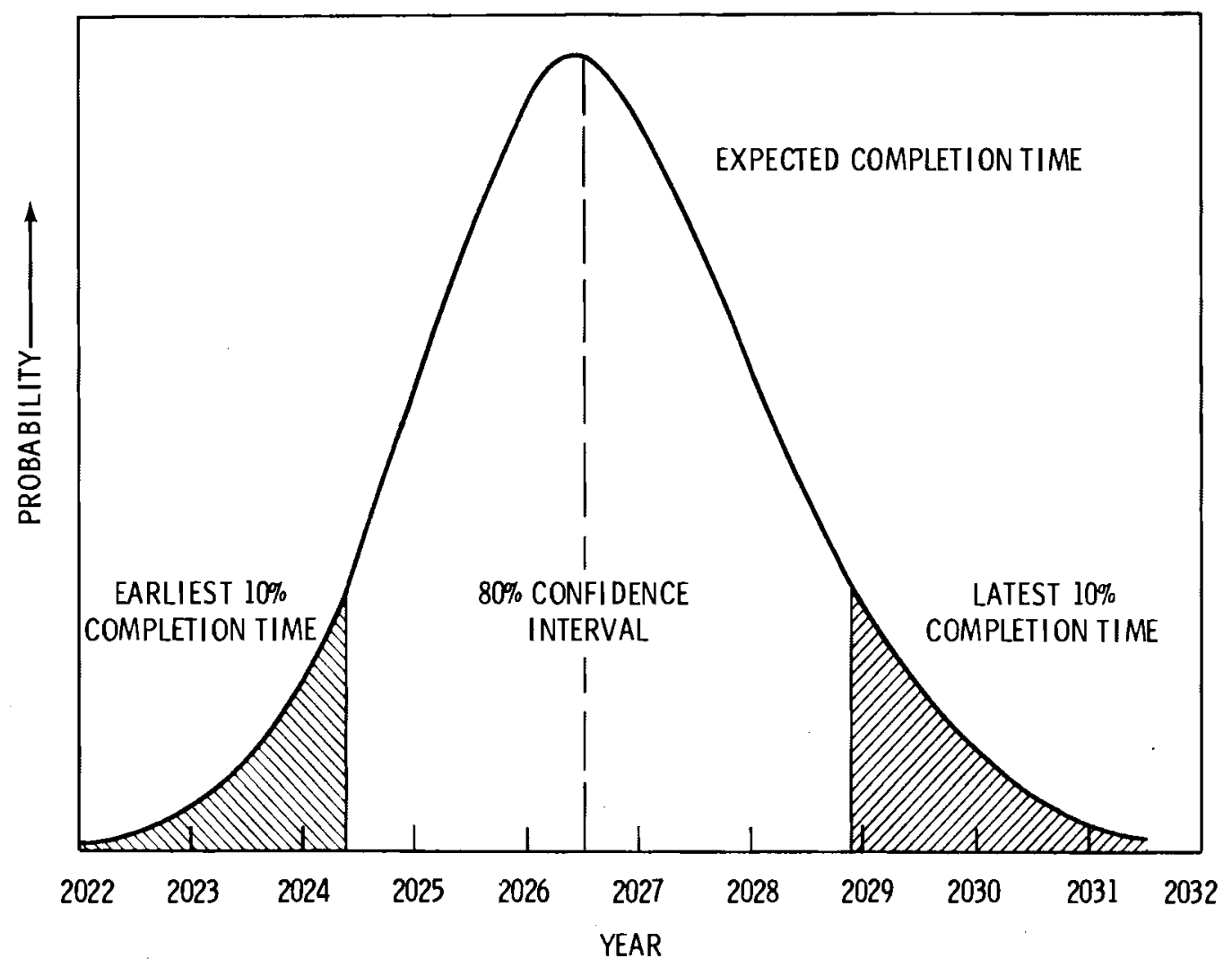

FIGURE 10. Probable Year of Completion of Sequential Strategy

TABLE 4. Standard Deviation of Strategy Completion Dates and $80 \%$ Confidence Interval

\begin{tabular}{|c|c|c|c|c|}
\hline Strategy & $\begin{array}{c}\text { Expected } \\
\text { Date } \\
\end{array}$ & $\begin{array}{l}\text { Standard } \\
\text { Deviation }\end{array}$ & $\begin{array}{l}80 \% \text { Confic } \\
\text { Early } \\
\text { Completion }\end{array}$ & $\begin{array}{c}\text { e Interval } \\
\text { Late } \\
\text { Completion }\end{array}$ \\
\hline A--Sequential & 2026.5 & 1.59 & 2024.5 & 2028.5 \\
\hline B--Delayed Sequential & 2031.5 & 1.59 & 2029.5 & 2033.5 \\
\hline C--Compressed & 2014.5 & 1.12 & 2013.0 & 2015.5 \\
\hline D--Delayed Compressed & 2019.5 & 1.13 & 2018.0 & 2020.5 \\
\hline E--Component Testing & 2019.0 & 1.37 & 2017.5 & 2021.0 \\
\hline F--Direct Prototype & 2009.0 & 1.37 & 2007.5 & 2010.5 \\
\hline G--Direct Replicate & 2011.0 & 1.26 & 2009.0 & 2012.0 \\
\hline
\end{tabular}


have greater, rather than less, uncertainty than a sequential approach. However, in the opinion of scheduling experts, the greatest contributor to time uncertainty is the loss of skilled design and licensing personnel. Whenever this cadre is dispersed, as is the case in the sequential approaches, the effects of attrition of personnel override the positive effects gained from reactor operating experience.

The completion dates can be compared to the competitive dates in several ways. One of these is illustrated in Figure 11. Using the $80 \%$ confidence intervals described above, the completion dates were compared to the FBR's competitive dates. Strategies E, F, and G produced 1000-MWe commercial FBRs; hence, they were compared to a different range of competitive dates than were the other four strategies. Notice that strategies $A$ and $B$ fall squarely within the range of competitive dates. If the analysis went no further, the $A$ and B strategies would appear superior.

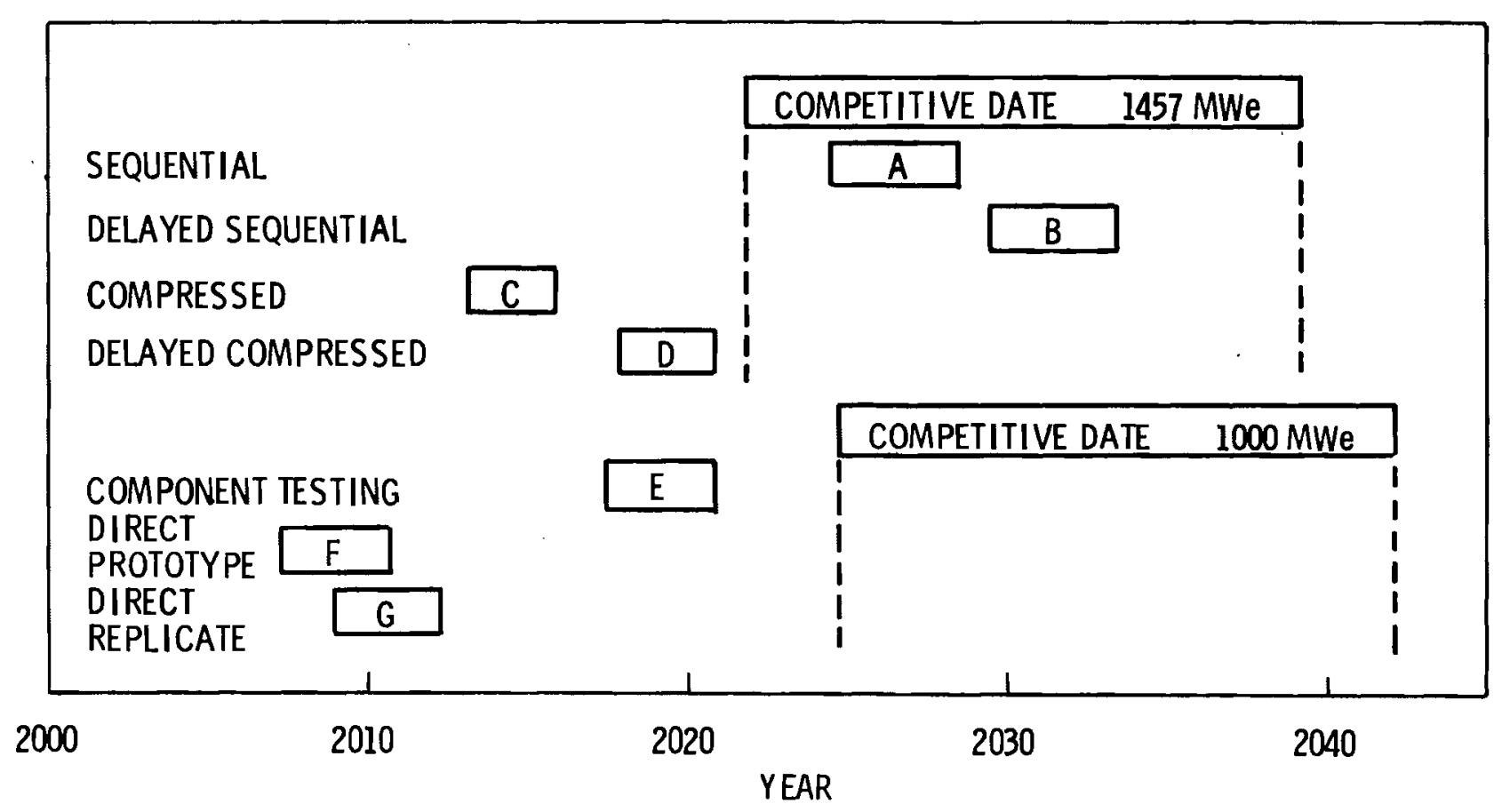

FIGURE 11. Comparison of Completion and Competitive Dates for an $80 \%$ Confidence Interva 1 
Another comparison of dates results from calculating the probability that a strategy will develop a commercial breeder on or before the date it is competitive. This calculation is called the success probability. Results of that calculation are show in Table 5. Note that only strategies $A$ and $B$ have any significant probability of not being ready when they are needed. The significance of this will become more apparent when we consider the impact of early and late risks.

TABLE 5. Strategy Success Probabilities

\begin{tabular}{lc}
\multicolumn{1}{c}{ Strategy } & Success Probability \\
A--Sequential & 0.65 \\
B--Delayed Sequential & 0.36 \\
C--Compressed & 1.0 \\
D--Delayed Compressed & 0.98 \\
E--Component Testing & 1.0 \\
F--Direct Prototype & 1.0 \\
G--Direct Replicate & 1.0
\end{tabular}

The risks of being "too early" and "too late" were described in Section 2.4. We found that the magnitude of the economic risk of being late by a given time period (say 5 years) was far greater than that of being early by a like time. This conclusion is intuitively satisfying, for in the case of the "early" development, the R\&D funds will have been spent a few years too soon; several extra years will pass before the FBR is competitive and is ordered by the utilities. In the "late" case the FBR will not be at a commercial stage on time and many less efficient plants must be built. Thus, the energy costs will be higher than necessary, and the impact on the economy will be large.

The calculated risks are shown in Table 6 . As could be anticipated from success probability calculations, only the sequential strategies ( $A$ and $B$ ) show any significant "late" risks. 
TABLE 6. Early and Late Risks (Discounted at $5 \%$ to 1980 )

\begin{tabular}{|c|c|c|}
\hline Strategy & $\begin{array}{l}\text { Early Risks } \\
\text { (Billion \$) }\end{array}$ & $\begin{array}{c}\text { Late Risk } \\
\text { (Billion \$) } \\
\end{array}$ \\
\hline A--Sequential & 0.34 & 8.28 \\
\hline B--Delayed Sequential & 0.18 & 28.27 \\
\hline C--Compressed & 1.40 & 0.00 \\
\hline D--Delayed Compressed & 1.02 & 0.21 \\
\hline E--Component Testing & 1.60 & 0.03 \\
\hline F--Direct Prototype & 2.79 & 0.00 \\
\hline G--Direct Replicate & 2.80 & 0.00 \\
\hline
\end{tabular}

Net strategy benefits consist of a combination of all the benefits, costs, and risks that are expected for a strategy:

net benefits = expected benefits - (expected costs) - (total risks)

Table 7 lists the values of net benefits calculated for the strategies. Note that the strategies that produce a large FBR generally exhibit higher net benefits than do the strategies ( $E, F$, and $G$ ) that produce a 1000-MWe FBR.

TABLE 7. Strategy Net Benefits

\begin{tabular}{lc}
\multicolumn{1}{c}{ Strategy } & $\begin{array}{c}\text { Net Benefiłs) } \\
(\text { Billion \$) }\end{array}$ \\
\cline { 1 - 1 } A--Sequential & 56.4 \\
B--Delayed Sequential & 37.5 \\
C--Compressed & 64.2 \\
D--Delayed Compressed & 64.4 \\
E--Component Testing & 45.2 \\
F--Direct Prototype & 43.4 \\
G--Direct Replicate & 43.2
\end{tabular}

(a) Discounted to 1980 at $5 \%$. 
The exception to this rule is the Delayed Sequential strategy (B), which exhibits a large late risk term. The mathematical techniques used to calculate this criterion are discussed in Appendix B of Fraley and Burnham (1981).

In an analys is of worst possible outcomes we used some of the tails of the distribution curves. An example of such a worst case outcome can be imagined by looking at the cost of a strategy's being completed at the latest probable date combined with the earliest probable date that the FBR would be competitive; this indicates a measure of the maximum late risk. A combination of the earliest probable completion dates with the latest probable competitive dates gives a measure of maximum early risk.

\subsection{RANKING OF STRATEGIES}

The strategies can be compared in a number of ways based on the analyses described above. We compared strategies based on the following three criteria:

economic: maximize the net benefit

risk averse: minimize the total risks

insurance: guard against the worst possible outcome, i.e., maximum late risk.

Table 8 shows how the strategies rank on the basis of these three comparisons. Note that there is no significant difference between the net benefits of the two compressed strategies ( $C$ and $D$ ); hence, they are both ranked highest in this respect. Strategies $C, D$, and $E$ have comparable values for total risk and are ranked equally on this basis. When maximum late risk is considered, it is possible to differentiate between $C$ and $D$. 
TABLE 8. Summary of Strategy Rankings

\begin{tabular}{|c|c|c|c|}
\hline Strategy & $\begin{array}{c}\text { Net } \\
\text { Benefits } \\
\end{array}$ & $\begin{array}{c}\text { Risk } \\
\text { Averse } \\
\end{array}$ & $\begin{array}{c}\text { Maximum } \\
\text { Late } \\
\text { Risk } \\
\end{array}$ \\
\hline A-- Sequential & 3 & 6 & 6 \\
\hline B--Delayed Sequential & 7 & 7 & 7 \\
\hline C--Compressed & 1 & 1 & 1 \\
\hline D--Delayed Compressed & 1 & 1 & 5 \\
\hline E--Component Testing & 4 & 1 & 1 \\
\hline F--Direct Prototype & 4 & 4 & 1 \\
\hline G--Direct Replicate & 4 & 4 & 1 \\
\hline
\end{tabular}




\subsection{CONCLUSIONS}

Results of our probabilistic analyses indicate that the most likely time when an FBR coming on line will be commercially competitive is the decade 2025-2035. This is based on the expected rate of growth of the nuclear industry and the U.S. uranium resources.

Because higher benefits will accrue from a large FBR, those strategies $(A, B, C$, and $D)$ that produce a 1457-MWe model have an advantage over the other strategies. The risk of being late was found to be markedly higher than the risk of being early. Combining all of the benefits, risks, and costs indicated that the Compressed Strategy, which will produce a large commercial FBR on-line in about 33 years, is superior to the other strategies studied.

These conclusions indicate that a near-term decision to start a large developmental plant is prudent, for the probability of achieving an optimal strategy is enhanced by a steady, committed program which develops a commercial FBR on or before the time it is competitive. 


\section{REFERENCES}

Atomic Industrial Forum (AIF) Inc. 1979. "A Reassessment of U.S. Breeder Reactor Policy," Washington D.C.

Boege 1, A. J. and M. J. Clausen. 1981. Characterization of Alternative FBR Development Strategies. PNL-3596, Pac if ic Northwest Laboratory, Richland, Washington.

Boeing Engineering and Construction Co. 1981. LMFBR Conceptual Design Study Final Report: Developmental Plant Cost Estimate Report. CDS 400-5. Prepared for the Department of Energy, Seatt le, Washington.

Droutman, L. August 1980. "Breeders: Energy Insurance for an Uncertain Future." Presented at the American Soc iety of Mechanical Engineers Nuclear Engineering Conference, San Francisco, California.

Fraley, D. W. and J. B. Burnham. 1981. A Method for Selecting Fast Breeder Reactor Development Strategies in the Presence of Uncertainties. PNL-3598, Pac ific Northwest Laboratory, Richland, Washington.

Manne, A. S. 1974. "Electric ity Investment Under Uncertainty: Waiting for the Breeder." Energy. M. S. Macrakis, ed. The MIT Press, Cambridge, Massachusetts.

Manne, A. S. 1977. ETA-MACRO: A Model of Energy - Economy Interactions. EPRI-EA-592, Electric Power Research Institute, PaTo ATto, California.

Manne, A. S. and 0. S. Yu. 1975. "Breeder Benefits and Uranium Availability," Nuclear News, 18, January 1975.

Manne, A. S., R. J. Condap, and P. V. Precke1. 1981. ETA-MACRO: A User's Guide. EA-1724, Electric Power Research Institute, Palo Alto, California.

Piepe1, G. F. et al. 1981. Probabilistic Estimates of U.S. Uranium Supply. PNL-3595, Pac ific Northwest Laboratory, RichTand, Washington.

Richels, R. G. 1979. R \& D Under Uncertainty: A Study of the U.S. Breeder Reactor Program. Garland Publishing Co., New York and London.

Stauffer, T. R., R. S. Palmer, and H. L. Wyck off. 1975. An Assessment of the Economic Incentives for the Liquid Metal Fast Breeder Reactors. Breeder Reactor Corporation, Sunnyvale, California.

U.S. Atomic Energy Commission (AEC). 1974. Proposed Final Environmental Statement - Liquid Metal Fast Breeder Reactor Program. WASH-1535. U.S. Government Printing Office, Washington D.C. 
U.S. Department of Energy. 1980. Reactor and Fuel Cycle Descriptions. Volume 9 of Nuclear Proliferation and Civilian Nuclear Power: Report of the Nonprol iferation ATternative Systems Assessment Program. DOE/NE-0001/9, U.S. Government Printing Office, Washington, D.C.

White, M. K. and E. T. Merri11. 1981. Evaluation of the Commercial FBR Introduction Date. PNL-3597, Pac ific Northwest Laboratory, Richland, Washington. 
PNL -3600

UC-2,16,

51,78 ,

$79,79 \mathfrak{i}$

\section{DISTR IBUTION}

No. of

Copies

OFFSITE

A. A. Churm

DOE Patent Division

9800 South Cass Avenue

Argonne, IL 60439

Gary Boyer

United Nuc lear Homestake

P.0. Box 98

Grants, NM 87020

E. M. Craig

Dawn Mining Co.

P.0. Box 25

Ford, WA 99013

Simcha Golan

Bechtel National Inc.

Engineers and Constructors

Fifty Beale Street

P.0 Box 3965

San Francisco, CA 94119

Stanley M. Davies

General Electric Company

310 Deguigne Drive

P.0. Box 508

Sunnyvale, CA 94086

Tom Hand

Westinghouse Electric Corporation

P.0. Box 158

Madison, PA 15663

Tom DiFrancisco

Burns and Roe, Inc.

496 Kinderkamack Rad

Orade 11, NJ 07649
No. of

Copies

John H. Crowley

United Engineers and Constructors

300 South 17 Street

Philadelphia, PA 19101

George Garabedian

Stone and Webster Engineering Corp.

Power Divison

245 Summer Street

Boston, MA 02107

Judy Grange

Science Applications, Inc. 40 Denver Tech Center West

7925 E. Prentice

Englewood, CO 80111

Bob Miller

United Nuclear

Drawer QQ

Gallup, NM 87301

Charles Stanley

Kerr McGee

Box 218

Grants, NM 87020

C. L. Storrs

C-E Power Systems

Combustion Engineering, Inc.

1000 Prospect Hill Road

Windsor, CT 06095

440 DOE Technical Information Center

P.0. Box 62

Oak Ridge, TN 37830 
No. of

Copies

Noe 1 Gonzaga

S. M. Stoller Corporation 1250 Broadway

New York, NY 10001

10 J. P. Thereault

U.S. Department of Energy

Wah ington D.C. 20545

W. W. Ballard

U.S. Department of Energy

Washington D.C. 20545

S. T. Brewer

U.S. Department of Energy Washington D.C. 20545

Hugh Kendrick

U.S. Department of Energy Washington D.C. 20545

R. G. Staker

U.S. Department of Energy Washington D.C. 20545

J. R. Longenecker

U.S. Department of Energy

Washington D.C. 20545

John A. Patterson

U.S. Department of Energy

Washington D.C. 20545

Roger Gagne

U.S. Department of Energy

Washington D.C. 20545

Tom Dillon

U.S. Department of Energy

Washington D.C. 20545

Neal Goldenberg

U.S. Department of Energy

Washington D.C. 20545

Richie Williamson

U.S. Department of Energy

Washington D.C. 20545
No. of

Copies

Dave Bodde

U.S. Department of Energy

Washington D.C. 20545

Bob Bown

U.S. Department of Energy

Washington D.C. 20545

Eli Goodman

U.S. Department of Energy

Washington D.C. 20545

A. J. Snyder

U.S. Department of Energy

Washington D.C. 20545

Ross Humphreys

U.S. Department of Energy

Washington D.C. 20545

Tom Werner

U.S. Department of Energy

Washington D.C. 20545

D. M. Blanchfield

Grand Junction Office

U.S. Department of Energy

P.0. Box 2567

Grand Junction, CO 81501

B. Boyer

Grand Junction Office

U.S. Department of Energy

P.0. Box 2567

Grand Junction, CO 81501

M. E. Crew

Grand Junction office

U.S. Department of Energy

P.0. Box 2567

Grand Junction, CO 81501

D. L. Curry

Grand Junction Office

U.S. Department of Energy

P.0. Box 2567

Grand Junction, CO 81501 
No. of

Copies

J. Franco

Grand Junction Office

U.S. Department of Energy

P.0. Box 2567

Grand Junction, CO 81501

P. de Vergi

Grand Junction Office

U.S. Department of Energy

P.0. Box 2567

Grand Junction, CO 81501

D. L. Everhart

Grand Junction Office

U.S. Department of Energy

P.0. Box 2567

Grand Junction, CO 81501

M. Hansen

Grand Junction Office

U.S. Department of Energy

P.0. Box 2567

Grand Junction, CO 81501

R. C. Malan

Grand Junction Office

U.S. Department of Energy

P.0. Box 2567

Grand Junction, CO 81501

L. Kovisars

MET Research

2403 Thomas Avenue

Dallas, TX 75201

R. A. McLaren

Union Carbide Nuclear Divison

P.0. Box P Mail Stop 17

Oak Ridge, TN 37830

C. E. Ford

Union Carbide Nuclear Divison

P.0. Box P Mail Stop 17

Oak Ridge, TN 37830
No. of

Copies

P. Rogers

Bendix Field Engineering Corp.

Grand Junction Operations

P.0. Box 1569

Grand Junction, CO 81501

Lewis Per 1

National Economic Research Association

5 Wor ld Trade Center

New York, NY 10048

Martin Becker

Rensselaer Poly Tech

Nuclear Eng ineering Department

Troy, NY 12181

Prof. Deverle P. Harris

University of Arizona

Department of Mining and

Geological Engineering

Tucson, AZ 85721

Prof. A. S. Manne

834 Esplanada Way

Stanford, CA 94305

Prof. J. Daniel Khazzoom

380 Kensington Way

San Francisco, CA 94127

Prof. Wayne J. Davis

University of Illinois

Dept. of General Engineering

Urbana, IL 61801

Dr. Lawrence Droutman

Westinghouse Electric Corporation

P.0. Box 158

Madison, PA 15663

Randa 11 L. Beatty

Science Applications, Inc.

800 0ak Ridge Turnpike

P.0. Box 843

Oak Ridge, TN 37830 
No. of

Copies

ONSITE

2 DOE Richland Operations Office

P. A. Craig

H. E. Ransom

70 Pacific Northwest Laboratory

C. H. Bloomster

A. J. Boege 1

J. B. Burnham (20)

L L. Clark

M. J. Clausen

B. M. Cole

D. E. Deonigi

D. A. Dingee

C. E. Elderk in

R. L. Engle

R. M. Fleischman (10)

D. L. Hall

C. R. Hann

H. Harty
No. of

Copies

A. J. Haverfield

C. M. Heeb

J. C. King

R. C. Liikala

L. W. Long

J. A. Mahaffey

R. P. Marsha 11

R. W. McKee

E. T. Merrill

D. F. Newman

R. E. Night ingale

D. E. Olesen

G. F. Piepel

R. J. Sorensen

A. M. Sutey

P. C. Walkup

M. K. White

W. R. Wiley

R. D. Widrig

T. L. Willke

L. D. Williams

Publishing Coordination $\mathrm{Ha}$ (2)

Technical Information (5) 